\title{
Stable isotope analysis of middle Miocene mammals from the Siwalik sub-Group of Pakistan
}

Muhammad Tahir Waseem, Abdul Majid Khan, Jay Quade, Anthony Krupa, David L. Dettman, Amtur Rafeh, and Rana Manzoor Ahmad

Acta Palaeontologica Polonica 66 (3), 2021: s123-s132 doi:https://doi.org/10.4202/app.00788.2020

Stable isotope analysis is pivotal for investigating the paleodiet and paleoecology of past mammals. In this paper, we analyzed thirty fossil enamel samples belonging to the families Suidae, Rhinocerotidae, and Deinotheriidae for $\delta 13$ Cenamel and $\delta 18$ Oenamel composition to investigate paleodiet and paleoecology of middle Miocene mammals of the Siwalik sub-Group of Pakistan. The three mammalian groups, when combined together, yielded an average $\delta 13$ Cenamel value of $-12.2 \pm 2 \%$, indicating a pure to nearly pure $\mathrm{C} 3$ diet. Suids show slightly higher 813 Cenamel values of $-11.2 \pm 1.4 \%$ when compared to rhinocerotids and deinotheres (-12.3 $\pm 0.8 \%$ and $-12.5 \pm 1.3 \%$, respectively), which could be explained by selective foraging on new leaf shoots or feeding from open spaces. Alternatively, the differences in $\delta 13$ Cenamel could be due to different digestive physiologies and different enamel-diet enrichment factors. Members of all three families showed significant differences in $\delta 180$ Oenamel values, where suids yielded higher $\delta 180$ values of $-8.2 \pm 1.2 \%$ compared to rhinocerotids and deinotheres $(-11.4 \pm 1.8 \% \circ$ and $-10.4 \pm 1.7 \%$ o, respectively). Based upon these results, we assume that these mammals inhabited subtropical forests similar that of mid-Miocene of the Siwalik Group, India and Nepal. The modern analogues of such vegetation system are present in East and South of Myanmar, Nepal, and Malaya where precipitation is enough to support evergreen C3 forests. By contrast, today's floodplain environments in Pakistan are dominated by $\mathrm{C} 4$ grasses, and $\mathrm{C} 3$ vegetation is only present in non-floodplain settings.

Key words: Mammalia, paleoclimate, paleodiet, Miocene, Chinji Formation, Pakistan.

Muhammad Tahir Waseem [tahirmuhammad1213@gmail.com], Abdul Majid

Khan [majid.zool@pu.edu.pk] (corresponding author), and Amtur Rafeh [amturrafeh@gmail.com

], Department of Zoology, University of the Punjab, Lahore 54590, Pakistan.

Jay Quade[quadej@email.arizona.edu], Anthony Krupa [akrupa@email.arizona.edu

], and David L. Dettman [dettman@email.arizona.edu], Department of

Geosciences, University of Arizona, Tucson AZ 85721, USA. Rana

Manzoor Ahmad [manzoor.zoology@uo.edu.pk], Department of Zoology, University of Okara, Punjab 56300, Pakistan. 
This is an open-access article distributed under the terms of the Creative Commons Attribution License (for details please see creativecommons.org), which permits unrestricted use, distribution, and reproduction in any medium, provided the original author and source are credited.

Farif Full text $(996.6 \mathrm{kB})$ 